Address for Correspondence: Dr. Asha Basavareddy Department of Pharmacology, Sri Devaraj Urs Medical College, Tamak Kolar - 563 101, Karnataka, India. E-mail: dr.ashareddy@gmail.com

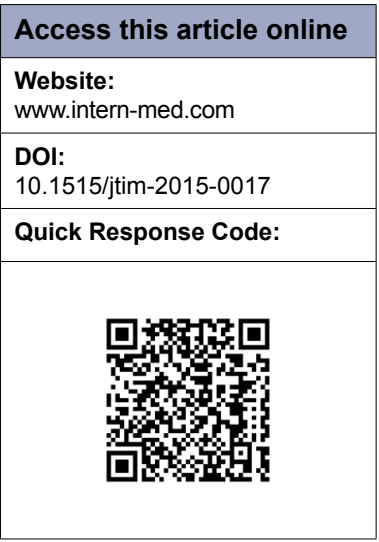

\title{
Seroprevalence of human immunodeficiency virus infection among tuberculosis patients at tertiary care combined hospital
}

\author{
Rakesh Basavareddy, Asha Basavareddy ${ }^{1}$, Shimoga Laxman Ravi², \\ Bilagumba Ramu Kiran ${ }^{2}$, Gadwalkar R Srikant ${ }^{2}$ \\ Department of Medicine, Basaveshwara Medical College and Hospital, Chitradurga, 'Department of \\ Pharmacology, Sri Devaraj Urs Medical College, Kolar, 'Department of Medicine, Vijayanagara Institute of \\ Medical Sciences, Bellary, Karnataka, India
}

\section{ABSTRACT}

Background and Objectives: Tuberculosis (TB) and the human immunodeficiency virus (HIV) infection have reached epidemic proportions in our country. This study was undertaken to know the seroprevalence of HIV infection among TB patients and to evaluate the various clinical features of TB in seropositive and seronegative patients. This study was undertaken in Vijayanagara Institute of Medical Sciences, Bellary. It was cross-sectional comparative observational study conducted from December 2010 to May 2012. Materials and Methods: A total of 100 consecutive patients diagnosed with TB satisfying inclusion criteria were selected for the study. All patients went through a detailed evaluation along with testing for HIV seroprevalence. Chi-square and Student's $t$-tests used to find the significance between two groups. Results: The overall HIV seroprevalence among TB patients was $8 \%$. Seroprevalence was highest in the age group between 31 and 40 years at $29.41 \%$ (odds ratio $[O R]=11.11, P=0.003$ ). It was found that seropositive TB patients were more likely to present with significant weight loss (OR $=19.25$, $P=0.000)$, and have lymphadenopathy $\mathrm{OR}=13.24, P=0.002)$ and oral candidiasis $(\mathrm{OR}=49.44$, $P=0.000)$ on examination. Bilateral chest radiographic involvement $(\mathrm{OR}=57.40, P=0.000)$ and the disseminated variety of the disease $(O R=29.67, P=0.001)$ are also more probable. Conclusions: Human immunodeficiency virus seroprevalence is quite high among TB patients in Bellary. During the evaluation of TB patients, the possibility of HIV co-infection should be kept in mind, and thus adequate knowledge of the likely clinical features is absolutely necessary.

Key words: Human immunodeficiency virus, seroprevalence, tuberculosis

\section{INTRODUCTION}

Tuberculosis (TB) has been one of the most significant infections causing human disease. In tropical countries, TB remains a leading cause of death. Poverty, overpopulation, inattention to tubercular services, and as a result of the human immunodeficiency virus (HIV)/ acquired immunodeficiency syndrome (HIV/AIDS) epidemic there are more cases of TB today than at any previous time in human history. ${ }^{[1]}$ Following its advent HIV/AIDS relentlessly spread around the world with no signs of regression. ${ }^{[2]}$ In 1993, World Health Organization (WHO) declared TB a "global emergency." In our country, the overall prevalence of HIV is $<1 \%$ and India continues to be in the category of low prevalence countries. However, this statistic blurs the actual picture of the pandemic in our populous country. In the year 2011, 2.71 million people were estimated to be infected with HIV in India. ${ }^{[2]}$ The other major problem that threatens the TB control is the emergence of multi-drug resistant tuberculosis. ${ }^{[1,3]}$ The immunosuppression as a result of HIV infection activates the latent TB infection and those infected spreading the 
bacilli in families, communities and health care settings significantly undermining TB control programs. ${ }^{[4,5]}$

Goals for TB include a worldwide cure rate of $85 \%$ and a case detection rate of $70 \%$ by 2015 . Goals for HIV include treating 3 million people with HIV infection in developing countries with antiretroviral drugs by 2015 . The Millennium Development Goals include targets for improved child health and survival and for improved control of priority communicable diseases (including TB and HIV) by 2015. Progress in improving TB/HIV clinical care will contribute to achieving these goals. Clinicians have a vital contribution to make, not only to the clinical care of patients, but also to public health. ${ }^{[6]}$ Hence, we have undertaken this study to determine the seroprevalence of HIV infection among TB patients and to compare the clinical features of TB in HIV seropositive and seronegative patients.

\section{MATERIALS AND METHODS}

This was a prospective cohort study consisting 100 TB patients on outpatient department basis and inpatients admitted to VIIMS, Bellary from December 2010 to June 2012. The study protocol was approved by institutional ethics committee. The patients diagnosed with TB as per the case definitions of the Revised National Tuberculosis Control Program (RNTCP) and willing to give informed written consent were included in the study. ${ }^{[7]}$ Detailed history regarding the illness was recorded. A thorough physical examination of all the systems was carried out. Appropriate laboratory and radiological investigations were done as required pertaining to each case.

All the patients were screened for HIV after counseling. Serum samples were screened for HIV using Comb AIDS test of Pareeksha, a reagent kit evaluated and recognized by WHO. All reactive samples were subjected to TRILINE and TRI SPOT test confirmation of HIV. As per WHO guidelines, when the HIV reactive sample in the screening test is further subjected to supplemental tests and again found to be HIV reactive, the positive predictive value of the same is $99.99 \% .{ }^{[8]}$ These cases were taken as HIV positive.
All patients were assigned categories as per the RNTCP. ${ }^{[7]}$ Category I - (i) new sputum smear-positive (ii) new sputum smear-negative (iii) New extrapulmonary. Category II - (i) sputum smear-positive relapse (ii) sputum smear-positive failure (iii) sputum smear-positive treatment after default.

History, examination, investigations, and diagnosis were recorded in the form of a proforma.

\section{Statistical analysis}

The statistical software SPSS 11.0 and Systat 8.0 were used for the analysis of the data. The Chi-square and Fisher exact test have been used to find the significance of proportions of various Demographic characteristics, symptoms, signs, Chest X-ray findings, and Diagnostic categories. The odds ratio $(\mathrm{OR})$ has been computed to find the relationship of above-mentioned variables for seroprevalence. Student's $t$-test to find the significance difference of means for the body mass index (BMI), hemoglobin $(\mathrm{Hb})$ percentage, and total count between seropositive and seronegative TB patients.

\section{RESULTS}

A total of 100 patients, 81 males and 19 females diagnosed with TB were taken for the study. Of them, eight were seropositive, giving an overall seroprevalence of HIV among all forms of TB as $8 \%$. The patients in the age group 21-30 2.02 (OR) times more likely to be seropositive with $P=0.394$ and the patients in the age group of 31-40 are $11.11(\mathrm{OR})$ times more likely to be seropositive with $P=0.003$ compared to other age groups as shown in Table 1.

Table 2 shows male TB patients are $1.70(\mathrm{OR})$ times more likely to be seropositive compared to female TB patients but are not statistically significant.

Agriculturist TB patients are $2.68(\mathrm{OR})$ times more likely to be seropositive with $P=0.225$ and drivers among the TB patients are 4.57 (OR) times more likely to be seropositive compared to other occupation $P=0.287$ and the TB patients in service category are 2.05 (OR)

Table 1: Age and gender distribution in TB patients

\begin{tabular}{|c|c|c|c|c|c|}
\hline \multirow[t]{2}{*}{ Age in years } & \multicolumn{2}{|c|}{ Male $(n=81)$} & \multicolumn{2}{|c|}{ Female $(n=19)$} & \multirow{2}{*}{$\begin{array}{c}\text { Total }(n=100) \\
\text { Number }\end{array}$} \\
\hline & Number & Percentage & Number & Percentage & \\
\hline $15-20$ & 3 & 3.70 & - & - & 3 \\
\hline $21-30$ & $19(2,10.5 \%)$ & 23.46 & $5(1,20 \%)$ & 26.31 & $24(3,12.5 \%)$ \\
\hline $31-40$ & $13(5,38.46 \%)$ & 16.05 & 4 & 21.05 & $17(5,29.41 \%)$ \\
\hline $41-50$ & 22 & 27.16 & 5 & 26.32 & 27 \\
\hline $51-60$ & 16 & 19.75 & 4 & 21.05 & 20 \\
\hline$>60$ & 8 & 9.87 & 1 & 5.26 & 9 \\
\hline Mean age & $43.12 \pm 13.85$ & & $41.32 \pm 12.82$ & & $42.78 \pm 13.61$ \\
\hline
\end{tabular}

OR numbers in parenthesis are seropositive TB patients, followed by the percentage. TB: Tuberculosis, OR: Odds ratio 
Table 2: HIV seroprevalence among TB patients according to gender

\begin{tabular}{|c|c|c|c|c|c|}
\hline \multirow[t]{2}{*}{ Gender } & \multicolumn{2}{|c|}{ HIV+ } & \multicolumn{2}{|c|}{ HIV- } & \multirow{2}{*}{$\begin{array}{c}\text { Total } \\
\text { Number }\end{array}$} \\
\hline & Number & Percentage & Number & Percentage & \\
\hline Male & 7 & 8.64 & 74 & 91.36 & 81 \\
\hline Female & 1 & 5.26 & 18 & 94.74 & 19 \\
\hline Overall & 8 & 8.00 & 92 & 92.00 & 100 \\
\hline
\end{tabular}

TB: Tuberculosis, HIV: Human immunodeficiency virus

Table 3: HIV seroprevalence among TB patients according to occupation

\begin{tabular}{lcccccc}
\hline \multirow{2}{*}{ Occupation } & \multicolumn{2}{c}{ HIV+ } & & \multicolumn{2}{c}{ HIV- } & Total \\
\cline { 2 - 3 } \cline { 5 - 7 } \cline { 5 - 7 } & Number & Percentage & & Number & Percentage & \\
\hline Agriculturist & 4 & 13.79 & & 25 & 86.21 & 29 \\
Service & 1 & 14.29 & & 6 & 85.71 & 7 \\
(clerk/tailor) & & & & & & \\
Drivers & 1 & 25.00 & & 3 & 75.00 & 4 \\
Housewives & 1 & 5.88 & & 16 & 94.12 & 17 \\
Laborers & 1 & 3.03 & & 32 & 96.96 & 33 \\
Others & - & & & 10 & 100.00 & 10 \\
\hline
\end{tabular}

TB: Tuberculosis, HIV: Human immunodeficiency virus times more likely to be seropositive with $P=0.453$ as shown in Table 3.

TB patients in the urban area are 2.28 (OR) more likely to be seropositive compared to the rural area with $P=0.264$. Seroprevalence in not statistically associated with the marital status or past history of TB $(P>0.05)$. The association of symptoms with seroprevalence in TB patients is shown in Table 4 and association with signs shown in Table 5.

Table 6 shows the association of chest X-ray with seroprevalence in TB patients. Table 7 shows an association of diagnosis with seroprevalence in TB patients.

\section{DISCUSSION}

A total of 100 patients, 81 male and 19 female diagnosed with TB were included in the study. The seroprevalence of HIV among all forms of TB was $8 \%$. Our study found that seroprevalence rates among men were $8.64 \%$, women

Table 4: Association of symptoms with seroprevalence in TB patients

\begin{tabular}{|c|c|c|c|c|c|c|c|}
\hline \multirow[t]{2}{*}{ Symptoms } & \multicolumn{2}{|c|}{ HIV+ } & \multicolumn{2}{|c|}{ HIV- } & \multirow[t]{2}{*}{ Total } & \multirow[t]{2}{*}{$P$} & \multirow[t]{2}{*}{ OR (HIV+) } \\
\hline & Number & Percentage & Number & Percentage & & & \\
\hline Cough & 3 & 3.70 & 78 & 96.30 & 81 & $0.006 * *$ & 0.11 \\
\hline Hemoptysis & - & - & 17 & 100.00 & 17 & 0.345 & - \\
\hline Breathlessness & 3 & 12.50 & 21 & 87.50 & 24 & 0.394 & 2.03 \\
\hline Fever & 6 & 6.59 & 85 & 93.41 & 91 & 0.152 & 0.25 \\
\hline Constitutional symptoms & 8 & 10.96 & 65 & 89.04 & 73 & 0.104 & 3.32 \\
\hline Significant weight loss & 8 & 22.86 & 27 & 77.14 & 35 & $0.000 * *$ & 19.25 \\
\hline Seizures & 2 & 18.18 & 9 & 81.82 & 11 & 0.213 & 3.07 \\
\hline Headache & 1 & 25.00 & 3 & 75.00 & 4 & 0.287 & 4.24 \\
\hline Altered sensorium & - & & 9 & 100.00 & 9 & $>0.05$ & - \\
\hline Symptoms of MI & 2 & 16.67 & 10 & 83.33 & 12 & 0.253 & 2.65 \\
\hline Neck swelling & - & - & 4 & 100.00 & 4 & $>0.05$ & - \\
\hline Gl symptoms & 1 & 25.00 & 3 & 75.00 & 4 & 0.287 & 4.24 \\
\hline CSW & 7 & 70.00 & 3 & 30.00 & 10 & $0.000 * *$ & 207.67 \\
\hline
\end{tabular}

${ }^{*}$ Statistical significance at $5 \%,{ }^{*}$ Statistical significance at $1 \%,{ }^{a}$ Near statistical significance. TB: Tuberculosis, OR: Odds ratio, HIV: Human immunodeficiency virus, Ml: Myocardial infarction, Gl: Gastrointestinal, CSW: Commercial sex worker

Table 5: Association of signs with seroprevalence in TB patients

\begin{tabular}{|c|c|c|c|c|c|c|c|}
\hline \multirow[t]{2}{*}{ Signs } & \multicolumn{2}{|c|}{ HIV+ } & \multicolumn{2}{|c|}{ HIV- } & \multirow[t]{2}{*}{ Total } & \multirow[t]{2}{*}{$P$} & \multirow[t]{2}{*}{ OR (HIV+) } \\
\hline & Number & Percentage & Number & Percentage & & & \\
\hline Pallor & 6 & 10.71 & 50 & 89.29 & 56 & 0.460 & 2.52 \\
\hline Jaundice & 1 & 20.00 & 4 & 80.00 & 5 & 0.347 & 3.14 \\
\hline Clubbing & 4 & 12.12 & 29 & 87.88 & 33 & 0.434 & 2.17 \\
\hline Edema & 1 & 33.33 & 2 & 66.67 & 3 & 0.223 & 6.43 \\
\hline Skin infections & 1 & 14.29 & 6 & 85.71 & 7 & 0.453 & 2.05 \\
\hline Lymphadenopathy & 6 & 26.08 & 17 & 73.91 & 23 & $0.002 * *$ & 13.24 \\
\hline Oral thrush & 5 & 62.50 & 3 & 37.50 & 8 & $0.000 * *$ & 49.44 \\
\hline Respiratory signs & 7 & 13.46 & 45 & 86.54 & 52 & 0.061 & 7.31 \\
\hline Abdominal signs & 4 & 36.36 & 7 & 63.64 & 11 & 0.005 & 12.14 \\
\hline CNS signs & 3 & 15.00 & 17 & 85.00 & 20 & 0.196 & 2.65 \\
\hline
\end{tabular}

*Statistical significance at $5 \%,{ }^{*}$ Statistical significance at $1 \%,{ }^{a}$ near statistical significance. TB: Tuberculosis, OR: Odds ratio, HIV: Human immunodeficiency virus, CNS: Central nervous system 


\begin{tabular}{|c|c|c|c|c|c|c|c|}
\hline \multirow[t]{2}{*}{ Chest X-ray findings } & \multicolumn{2}{|c|}{ HIV+ } & \multicolumn{2}{|c|}{ HIV- } & \multirow[t]{2}{*}{ Total } & \multirow{2}{*}{$\begin{array}{c}\text { Significance } \\
\text { (P value by } \\
\chi^{2} \text { or Fisher's } \\
\text { exact test) }\end{array}$} & \multirow[t]{2}{*}{ OR (HIV+) } \\
\hline & Number & Percentage & Number & Percentage & & & \\
\hline UL investigation & 1 & 1.96 & 50 & 98.04 & 51 & $0.029 *$ & 0.12 \\
\hline BL investigation & 7 & 41.17 & 10 & 58.82 & 17 & $0.000 * *$ & 57.40 \\
\hline UL (C/FC/F) & - & - & 10 & 100.00 & 10 & $>0.05$ & - \\
\hline $\mathrm{BL}(\mathrm{C} / \mathrm{FC} / \mathrm{F})$ & - & - & 1 & 100.00 & 1 & $>0.05$ & - \\
\hline UL (Infil/CO) & - & - & 31 & 100.00 & 31 & $0.055^{a}$ & - \\
\hline BL (Infil/CO) & 2 & 28.57 & 5 & 71.43 & 7 & $0.096^{a}$ & 5.80 \\
\hline UL PE & 1 & 5.00 & 19 & 95.00 & 20 & $>0.05$ & 0.55 \\
\hline BL PE & - & - & - & - & - & - & - \\
\hline $\mathrm{RP}$ & 3 & 100.00 & - & - & 3 & $0.000 * *$ & $\approx 55.20$ \\
\hline MM & 1 & 25.00 & 3 & 75.00 & 4 & 0.287 & 4.24 \\
\hline
\end{tabular}

*Statistical significance at 5\%, **Statistical significance at 1\%, aNear statistical significance. UL: Unilateral, BL: Bilateral, F: Fibrosis/fibrothorax, C: Cavitation, FC: Fibrocavity, CO: Consolidation, Infil: Infiltration, PE: Pleural effusion, RP: Reticulonodular pattern, MM: Miliary mottling, OR: Odds ratio, TB: Tuberculosis, HIV: Human immunodeficiency virus

Table 7: Association of diagnosis with seroprevalence in TB patients

\begin{tabular}{|c|c|c|c|c|c|c|c|}
\hline \multirow[t]{2}{*}{ Diagnosis } & \multicolumn{2}{|c|}{ HIV+ } & \multicolumn{2}{|c|}{ HIV- } & \multirow[t]{2}{*}{ Total } & \multirow[t]{2}{*}{$P$} & \multirow[t]{2}{*}{ OR (HIV+) } \\
\hline & Number & Percentage & Number & Percentage & & & \\
\hline PTB & 2 & 3.85 & 50 & 96.15 & 52 & 0.149 & 0.28 \\
\hline PTB Sp + & 1 & 2.22 & 44 & 97.78 & 45 & $0.070 *$ & - \\
\hline PTB Sp - & - & - & 7 & 100.00 & 14 & 0.596 & - \\
\hline ЕРТВ & 2 & 4.88 & 39 & 96.12 & 41 & 0.466 & 0.44 \\
\hline EPTB PE & - & - & 14 & 100.00 & 14 & 0.596 & - \\
\hline EPTB TBL & - & - & 4 & 100.00 & 4 & 0.895 & - \\
\hline EPTB ABTB & 1 & 25 & 3 & 75 & 4 & 0.287 & 4.24 \\
\hline ЕРТВ ТВM & 1 & 5.56 & 17 & 94.44 & 18 & 0.985 & 0.63 \\
\hline EPTB TBS & - & - & 1 & 100.00 & 1 & 0.876 & - \\
\hline DTB/MTB & 4 & 57.14 & 3 & 42.86 & 7 & $0.001 * *$ & 29.67 \\
\hline DTB Sp + & 2 & 66.67 & 1 & 33.33 & 3 & $0.016^{*}$ & 30.33 \\
\hline DTB Sp - & 2 & 50.00 & 2 & 50.00 & 4 & $0.031 *$ & 15.01 \\
\hline
\end{tabular}

*Statistical significance at $5 \%,{ }^{*}$ Statistical significance at $1 \%$, aNear statistical significance. PTB: Pulmonary tuberculosis, EPTB: Extra pulmonary tuberculosis, PE: Pleural effusion, TBL: Tubercular lymphadenopathy, ABTB: Abdominal tuberculosis, TBM: Tubercular meningitis, TBS: Tuberculosis spine, DTB: Disseminated tuberculosis, MTB: Miliary tuberculosis, $\mathrm{Sp}+$ : Sputum positive, $\mathrm{Sp}-$ : Sputum negative, TB: Tuberculosis, HIV: Human immunodeficiency virus, OR: Odds ratio

$5.26 \%$ and was highest in the age group between 31 and 40 years at 29.41\% [Tables 1 and 2] and had a significant association with seroprevalence $(\mathrm{OR}=11.11, P=0.003)$. Among the occupations [Table 3], seroprevalence was highest among drivers at $25 \%$. However, most of the seropositive patients were from the agricultural background accounting for half the cases. The number of seropositive cases was equally distributed between urban and rural regions. Seroprevalence was found to be higher among the urban group of patients at $12.5 \%$ when compared to $5.88 \%$ among the rural group. Seroprevalence was $8.33 \%$ and $6.67 \%$ among the married and single patients, respectively. Patients with no previous history of TB had a seroprevalence of $8.86 \%$ whereas among patients with the previous history of the disease only $4.76 \%$ were seropositive $(P>0.05)$.

Patients presented with various symptoms [Table 5] though $81 \%$ of patients complained of cough only $3.7 \%$ of those patients were seropositive $(\mathrm{OR}=0.11, P=0.006)$. This can be explained by the fact that $75 \%$ of the seropositive cases had either extrapulmonary or disseminated TB (DTB) whereas only $25 \%$ had the pulmonary variety of the disease. None of the seropositive cases had hemoptysis. Seroprevalence was $12.5 \%$ among patients complaining of breathlessness $(\mathrm{OR}=2.03, P=0.394) .6 .59 \%$ of patients complaining of fever were seropositive $(\mathrm{OR}=0.25$, $P=0.152$ ). Only $35 \%$ of patients complained of significant weight loss but again all the seropositive cases in our study had this complaint and seroprevalence was $22.86 \%$ $(\mathrm{OR}=19.25, P=0.000)$. Patients with symptoms of seizures, headache, meningeal irritation, and gastrointestinal disturbances did not have any significant association with seroprevalence. Among patients who gave a history of contact with a commercial sex worker, there was a high seroprevalence of $70 \%(\mathrm{OR}=207.67, P=0.000)$.

Patients had a wide spectrum of clinical signs on examination [Table 5]. 26.08\% of patients with lymphadenopathy were seropositive $(\mathrm{OR}=13.24, P=0.002)$. Oral candidiasis 
was seen in eight of our patients and $62.5 \%$ of them were seropositive $(\mathrm{OR}=49.44, P=0.000)$. Clinical findings on respiratory system examination were quite common and seroprevalence was $13.46 \%(\mathrm{OR}=7.31, P=0.061)$. Seroprevalence was $36.36 \%$ among patients with signs on abdominal examination (OR $=12.14, P=0.005)$. Pallor, jaundice, clubbing, edema, skin infections, and neurological signs did not have any statistically significant association with seropositivity.

Nourishment was poor in most of the subjects of our study. Seropositive patients were significantly undernourished when compared to seronegative patients (BMI $18.01 \pm 1.91$ vs. $20.57 \pm 2.66 \mathrm{~kg} / \mathrm{m}^{2}, P=0.009$ ). The $\mathrm{Hb}$ percentage was significantly lower in seropositive patients $(8.64 \pm 1.07 \mathrm{~g} \%)$ than in seronegative patients $(9.89 \pm 1.73 \mathrm{~g} \%, P=0.047)$. Total leukocyte count was significantly lower in seropositive patients $(5512.50 \pm 1241.47 \mathrm{cells} / \mathrm{ml})$ than in seronegative patients $(1111.52 \pm 2252.18$ cells $/ \mathrm{ml}, P=0.000) .87 .5 \%$ of all seropositive cases had bilateral chest radiograph involvement. $41.17 \%$ of all patients with bilateral chest radiograph involvement were seropositive $(\mathrm{OR}=57.40$, $P=0.000$ ) [Table 6]. $28.57 \%$ of patients with bilateral parenchymal infiltration or consolidation were found to be seropositive $(\mathrm{OR}=5.80, P=0.096)$, however, there were none among those with unilateral parenchymal infiltration or consolidation. None of the seropositive cases had evidence of fibrosis, cavity or fibrocavity radiographically. All the patients with a reticulonodular pattern were seropositive $(\mathrm{OR}=55.50, P=0.000)$. Seroprevalence was $25 \%$ among those with miliary mottling $(\mathrm{OR}=4.24, P=0.287)$.

About $52 \%$ of cases in our study were of PTB but only $3.85 \%$ were seropositive $(\mathrm{OR}=0.28, P=0.149)$ [Table 7]. $4.88 \%$ of extra-pulmonary tuberculosis (EPTB) cases were seropositive $(\mathrm{OR}=0.44, P=0.466)$. Among the $\mathrm{EPTB}$ cases $12.5 \%$ of abdominal tuberculosis $(\mathrm{OR}=4.24, P=0.287)$ and $50 \%$ of tubercular meningitis $(\mathrm{OR}=0.63, P>0.05)$ cases were seropositive. $37.5 \%$ of all the seropositive patients were diagnosed with DTB/milliary TB. Among the sputum positive PTB patients seroprevalence was $2.22 \%$ $(\mathrm{OR}=0.16, P=0.070)$ and among the sputum negative patients there were no seropositive patients. However among DTB/miliary TB patients seroprevalence was 66.67\% (OR $=30.33, P=0.016)$ and $50 \%(\mathrm{OR}=15.00$, $P=0.031)$ among sputum positive and sputum negative patients, respectively. Seroprevalence was $10.14 \%$ and $4.76 \%$ among RNTCP Category I and II patients, respectively.

In Tamil Nadu, seroprevalence of HIV among TB was reported at $4.7 \%$ with the highest seropositivity rate among patients aged 30-39 years at 10.6\% during 2008-2009 92\% of the cases were found in the age group between 20 and 49. ${ }^{[9]}$ In Delhi seroprevalence increased from $0.4 \%$ in 1994-1999 to 8.4\% in 2008-2009. ${ }^{[10]}$ Sentinel surveillance done in Pune showed that seropositivity has increased from $10 \%$ in 1995 to $20.75 \%$ in $2010 .{ }^{[11]}$ In Thanjavur, seroprevalence was seen to increase from $0.59 \%$ in the year 1996 to $8.89 \%$ in $2008 .{ }^{[12]}$ Seroprevalence in Goa was reported to increase from $2.01 \%$ in 1995 to $6.9 \%$ in $2009 .{ }^{[13]}$ Studies have shown that seroprevalence has increased from $2.6 \%$ in $1995-1996$ to $11.7 \%$ in 2005-2006 in Mumbai. ${ }^{[14]}$

\section{CONCLUSIONS}

Seroprevalence of HIV among TB was found to be $8 \%$ in our study. The highest rates of seropositivity were between the ages of 31-40 years. Our study suggests male TB patients aged between 21 and 40 years should be targeted as they account for the majority of the cases. Patients of certain high-risk occupations and behavior should be screened.

Seropositive TB patients commonly present with weight loss. On examination, severe anemia, undernourishment, lymphadenopathy, and presence of opportunistic infections like oral candidiasis are quite common. Radiologically, bilateral involvement and atypical features are hallmarks of a dual infection. Seropositive patients also have a much higher chance of DTB.

Hence, taking all of this into consideration clinicians should maintain a high index of suspicion and is imperative to have a thorough understanding of the interactions between these two diseases.

\section{Conflicts of Interest}

None declared.

\section{REFERENCES}

1. Grange JM, Zumla AI. Tuberculosis. In: Cook GC, Alimuddin IZ, editors. Manson's Tropical Diseases.Saunders Elsevier; 2008. pp. 995-1052.

2. Sharma SK, Mohan A, Kadhiravan T. HIV-TB co-infection: Epidemiology, diagnosis \& management. Indian J Med Res 2005;121:550-67.

3. Gray SM. Tuberculosis and the human immunodeficiency virus infection. In: Rom WN Gray SM editors. Tuberculosis. 2nd ed. Boston: Little Brown and Company Inc.; 2008. p. 443-65.

4. Samuel NM, Alamelu C, Jagannath K, Rajan B. Detection of HIV infection in pulmonary tuberculosis patients. J Indian Med Assoc 1996;94:331-3.

5. Slotar D, Escalante P, Jones BE. Pulmonary manifestations of HIV/ AIDS in the tropics. Clin Chest Med 2002;23:355-67.

6. Harries A, Maher D, Graham S. TB/HIV A Clinical Manual. $2^{\text {nd }}$ ed. Geneva: (C) World Health Organization; 2004. p. 11.

7. Khatri GR. The Revised National Tuberculosis Control Program. A status report on the first 1,00,000 patients. Indian J Tuberc 
1999;46:157-66.

8. G.Kulkarni,V.S.Kavishwar,A.R.Chogle,etal.SeroprevalenceofHuman Immunodeficiency virusinfectioninaninfectiousdisease hospital. JAPI 2010;48;1160-1163.

9. Ramachandran R, Datta M, Subramani R, Baskaran G, Paramasivan $\mathrm{CN}$, Swaminathan S. Seroprevalence of human immunodeficiency virus (HIV) infection among tuberculosis patients in Tamil Nadu. Indian J Med Res 2003;118:147-51.

10. Sharma SK, Aggarwal G, Seth P, Saha PK. Increasing HIV seropositivity among adult tuberculosis patients in Delhi. Indian J Med Res 2003;117:239-42.

11. Narain JP, Pontali E, Tripathy S. Sentinel surveillance for HIV infection in tuberculosis patients in India.Indian J Tuberc. 2002;49:17-20.
12. Rajasekaran S, Uma A, Kamakshi S, Jeyaganesh D, Senthamizhchelvan A, Savithri S, et al. Trend of HIV infection in patients with tuberculosis in rural south India. Indian J Tuberc.2000;47:223-6.

13. Vasadevaiah V. HIV infection among tuberculosis patients. Indian J Tuberc 1997;44:97-8.

14. Mohanty KC, Basheer PM. Changing trend of HIV infection and tuberculosis in a Bombay area since 1988. Indian J Tuberc 1995;42:117-20.

How to cite this article: Basavareddy $\mathrm{R}$, et al. Seroprevalence of human immunodefi ciency virus infection among tuberculosis patients at tertiary care combined hospital. J Transl Intern Med 2015;3:130-135 